\title{
BMJ Open Snoring and incident chronic kidney disease: a community-based prospective cohort study
}

\author{
Changhyun Lee, ${ }^{1}$ Young Su Joo, ${ }^{1}$ Sangmi Lee, ${ }^{1}$ Shinchan Kang, ${ }^{1}$ \\ Joohwan Kim, ${ }^{1}$ Ki Heon Nam, ${ }^{1}$ Hae-Ryong Yun, ${ }^{1}$ Jong Hyun Jhee, ${ }^{2}$ \\ Hyoungnae Kim, ${ }^{3}$ Seung Hyeok Han, ${ }^{1}$ Tae-Hyun Yoo, ${ }^{1}$ Shin-Wook Kang, ${ }^{1}$ \\ Jung Tak Park ${ }^{1}$
}

To cite: Lee C, Joo YS, Lee S, et al. Snoring and incident chronic kidney disease: a community-based prospective cohort study. BMJ Open 2019;9:e030671. doi:10.1136/ bmjopen-2019-030671

- Prepublication history and additional material for this paper are available online. To view these files, please visit the journal online (http://dx.doi. org/10.1136/bmjopen-2019030671).

Received 03 April 2019 Revised 08 July 2019 Accepted 09 July 2019

Check for updates

(C) Author(s) (or their employer(s)) 2019. Re-use permitted under CC BY-NC. No commercial re-use. See rights and permissions. Published by BMJ.

${ }^{1}$ Department of Internal Medicine, College of Medicine, Institute of Kidney Disease Research, Yonsei University, Seoul, Republic of Korea ${ }^{2}$ Division of Nephrology and Hypertension, Department of Internal Medicine, Inha University College of Medicine, Incheon, Republic of Korea ${ }^{3}$ Division of Nephrology, Department of Internal Medicine, Soonchunhyang University Seoul Hospital, Seoul, Republic of Korea

Correspondence to

Dr Jung Tak Park;

JTPARK@yuhs.ac

\section{ABSTRACT}

Objectives Previous studies have shown that symptoms of sleep-disordered breathing are associated with metabolic derangements and vascular disease development. However, the relationship between snoring and renal function is not well investigated. The association between snoring and the development of incident chronic kidney disease (CKD) in subjects with normal renal function was evaluated.

Design Prospective cohort study.

Setting Ansung (rural community) and Ansan (urban community) cities.

Participants Community-based cohort participants aged 40-69 years.

Methods A total of 9062 participants in the AnsungAnsan cohort study were prospectively followed up from 2001 to 2014. The participants were classified into three groups: non-snorer, $<1$ day/week and $\geq 1$ day/week. The main outcome was incident CKD, which was defined as an estimated glomerular filtration rate of $<60 \mathrm{~mL} / \mathrm{min} / 1.73 \mathrm{~m}^{2}$ during the follow-up period.

Primary outcome Incident CKD.

Results The mean subject age was $52.0 \pm 8.9$ years, and $4372(48.2 \%)$ subjects were male. The non-snorer, $<1$ day/ week and $\geq 1$ day/week groups included 3493 (38.5\%), 3749 (41.4\%), and 1820 (20.1\%) subjects, respectively. Metabolic syndrome was more prevalent in the snoring groups than in the non-snoring group. Snoring frequency showed a significant positive relationship with age, waist:hip ratio, fasting glucose, total cholesterol (Tchol) and low-density lipoprotein cholesterol. During a mean follow-up of 8.9 years, 764 (8.4\%) subjects developed CKD. Cox proportional hazards model analysis revealed that the risk of CKD development was significantly higher in subjects who snored $\geq 1$ day/week than in non-snorers, even after adjustments for confounding factors (HR 1.23, $95 \% \mathrm{Cl} 1.09$ to $1.38, \mathrm{p}<0.01$ ).

Conclusion Snoring may increase the risk of CKD development in subjects with normal renal function.

\section{INTRODUCTION}

The prevalence of chronic kidney disease (CKD) is rapidly increasing worldwide despite blood glucose control and hypertension management, which are the main factors

\section{Strengths and limitations of this study}

- This study included a large number of healthy participants.

- The participants were prospectively followed up for a long duration.

- The self-reported questionnaires may limit reliability.

- The observational nature of the study limits the ascertainment of the cause-effect relationship.

that affect renal function. ${ }^{1}$ As established CKD is an irreversible condition, increasing emphasis has been placed on detecting highrisk patients and implementing early interventions. Therefore, identifying lifestyles and easy-to-detect habitual behaviours associated with the development of CKD is an important starting point of the process of reducing the burden associated with CKD. ${ }^{2}$

Snoring without apnoea is commonly considered as a mild form of obstructive sleep-disordered breathing. Although most people with obstructive sleep apnoea (OSA) complain of symptoms of snoring, the prevalence of actual OSA among snorers has been shown to vary. ${ }^{34}$ This suggests that snoring could occur independent of OSA. Reports have also proposed a possibility that several medical problems are related to snoring independent of the OSA status, suggesting that snoring by itself could have adverse clinical implications on medical conditions. ${ }^{56}$ Although snorers with OSA were not totally excluded, cumulative studies have also reported that snoring is associated with hypertension, cardiovascular diseases and stroke. ${ }^{7-9}$

Several previous studies have evaluated the effect of OSA on renal function. However, the results have been mixed and inconclusive. ${ }^{10-13}$ In addition, these studies evaluating the association of sleep-disordered breathing 
with renal function have focused on OSA rather than snoring.

Therefore, in order to investigate whether snoring affects renal function, the relationship between self-reported snoring and development of CKD was assessed in a prospective community-based cohort consisting of subjects with normal renal function. This investigation was based on the hypothesis that snoring may affect kidney function. The Korean Genome and Epidemiology Study (KOGES) cohort study data were used to assess this hypothesis since the cohort's objectives met the purpose of this evaluation.

\section{MATERIALS AND METHODS}

\section{Study population}

Data from the Ansung-Ansan cohort study were used. The Ansung-Ansan cohort study is an ongoing prospective study started in 2001 as part of the KoGES. Detailed profile and methods concerning the development of the cohort have been described previously. ${ }^{14}$ In brief, the cohort consists of residents aged 40 to 69 years from Ansung (rural community) and Ansan (urban community) city, which are located near the Korean capital of Seoul. Successive health examinations and surveys are being biennially performed from 2001. The baseline survey, which was carried out from 2001 to 2002, included 10030 participants. After excluding subjects whose baseline estimated glomerular filtration rate (eGFR) was
$<60 \mathrm{~mL} / \mathrm{min} / 1.73 \mathrm{~m}^{2}$, those with a past history of kidney disease, and those with missing data, a total of 9062 participants were included in this analysis (figure 1). The participants were traced until the sixth follow-up survey performed in 2014.

This study was carried out in accordance with the Declaration of Helsinki and was approved by the institutional review board of the Yonsei University Health System Clinical Trial Centre (4-2016-0900). All subjects were fully informed of the study contents, and they provided written informed consents for data use.

\section{Clinical and laboratory measurements}

All participants completed a comprehensive health examination and interview according to a site visit schedule. The health examination included evaluation of anthropometric indices and the collection of biological specimens for assessment.

The study participants completed interviewer-administered questionnaires that included questions on age, smoking and alcohol status, level of education and income, marital status, degree of physical activity and medical history. Anthropometric variables, including weight, abdominal girth and hips, were measured based on standard methods by skilled study workers, with the subjects wearing light clothing. Body mass index (BMI) was calculated as weight $(\mathrm{kg}) /$ height $\left(\mathrm{m}^{2}\right)$. Waist circumference was measured in a horizontal plane, midway between the inferior margin of the ribs and the superior border of

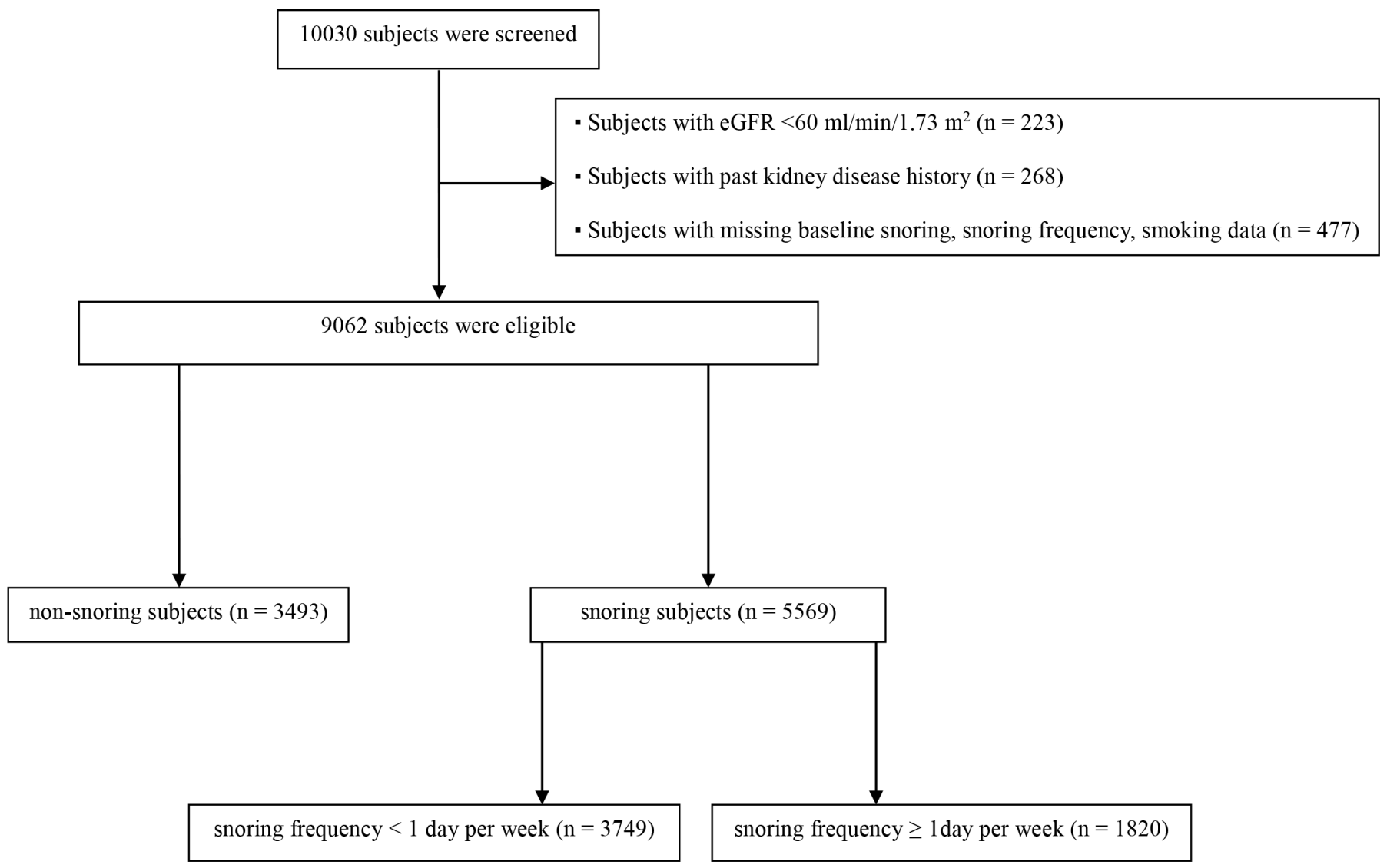

Figure 1 Flow diagram of the study cohort. eGFR, estimated glomerular filtration rate. 
the iliac crest. Waist:hip ratio (WHR) was calculated by dividing waist circumference to hip circumference. Blood pressure was measured by trained technicians using mercury sphygmomanometers (Baumanometer Standby; W.A. Baum Co., Copiague, NY, USA). Before blood pressure measurement, the subjects were instructed to relax in the sitting position for at least $10 \mathrm{~min}$. The mean of two blood pressure readings was used for data analyses.

After at least 8 hours of fasting, blood and urine samples were collected and delivered to a central laboratory (Seoul Clinical Laboratories, Seoul, Republic of Korea) within 24 hours of sampling. Plasma was separated by centrifugation (2000 rpm, $20 \mathrm{~min}$, at $4^{\circ} \mathrm{C}$ ), and biochemical measurements were immediately conducted. The plasma concentrations of glucose, Tchol, triglycerides (TGs) and high-density lipoprotein cholesterol (HDL-C) were measured enzymatically using a 747 Chemistry Analyzer (Hitachi, Tokyo, Japan). Low-density lipoprotein-cholesterol (LDL-C) was calculated using the Friedewald equation. ${ }^{15}$ Serum creatinine (Scr) was measured using Jaffe's method with a Hitachi Automatic Analyzer 7600 (Hitachi). eGFR was calculated using the Chronic Kidney Disease Epidemiology Collaboration equation: eGFR $\left(\mathrm{mL} / \mathrm{min} / 1.73 \mathrm{~m}^{2}\right)=141 \times \min (\mathrm{Scr} / \kappa, 1) \alpha \times \max (\mathrm{Scr} / \kappa$, 1 ) $-1.209 \times 0.993$ age (years) $\times 1.018$ (if female) $\times 1.159$ (if black), where $\kappa$ is 0.7 for women and 0.9 for men, $\alpha$ is -0.329 for women and -0.411 for men, min indicates the minimum of Scr/ $\mathrm{K}$ or 1 , and max indicates the maximum of $\mathrm{Scr} / \mathrm{K}$ or $1 .{ }^{16}$ Surveys inquiring on socioeconomic status and lifestyle were performed at baseline, while anthropometric measurements (blood pressure, body weight, height, and abdominal and hip circumference) and laboratory evaluations (serum Tchol, TG, HDL-C, blood urea nitrogen creatinine, $\mathrm{C}$ reactive protein, blood glucose, haemoglobin and haematocrit) were assessed at each follow-up visit. Serum albumin was accessed at baseline only.

\section{Sleep quality assessment}

Detailed information on sleep duration, quality and disorders, including habitual snoring, was collected using a self-reported sleep quality questionnaire at baseline. Snoring frequency was assessed using a 5-point scale: never, infrequently, sometimes (one to three nights/ week), often (four or five nights/week) and almost every night. Individuals were grouped into snorers (snoring at least one night/week and snoring less than one night/ week) and non-snorers. Subjects were also asked if they had insomnia (yes/no), had a difficulty falling asleep (yes/no), woke up during the night and were unable to fall back to sleep (yes/no), woke up too early in the morning (yes/no), had irregular sleeping time (yes/no), had the symptoms of restless legs syndrome (yes/no) and had experienced periodic limb movements during sleep (yes/no). The self-reported answers on snoring were confirmed by a bed partner or a family member in a subset of participants. In addition, excessive daytime sleepiness (EDS) was assessed using the Epworth sleepiness scale (ESS), with a score above 11 points indicating EDS. ${ }^{1718}$

\section{Definitions of metabolic syndrome (MetS)}

Based on the modified National Cholesterol Education Programme Adult Treatment Panel III criteria, MetS) was defined as the presence of three or more of the following components: (1) abdominal obesity, defined as a waist circumference of $\geq 90 \mathrm{~cm}$ for men and $\geq 85 \mathrm{~cm}$ for women (following Korean-specific cut-offs for abdominal obesity, defined by the Korean Society of Obesity); (2) hypertriglyceridemia, defined as a serum TG concentration of $\geq 150 \mathrm{mg} / \mathrm{dL}$; (3) low HDL cholesterol, defined as a serum HDL cholesterol concentration $<40 \mathrm{mg} / \mathrm{dL}$ for men and $<50 \mathrm{mg} / \mathrm{dL}$ for women; (4) high blood pressure, defined as a systolic blood pressure (SBP) of $\geq 130 \mathrm{~mm} \mathrm{Hg}$, diastolic blood pressure (DBP) of $\geq 85 \mathrm{~mm} \mathrm{Hg}$ or treatment with antihypertensive agents; and (5) high fasting glucose, defined as a fasting serum glucose level of $\geq 100 \mathrm{mg} / \mathrm{dL}$ or previously diagnosed type 2 diabetes. ${ }^{19} 20$

\section{Study outcome}

The primary endpoint was incident $\mathrm{CKD}$, which was defined as two or more consecutive eGFR $<60 \mathrm{~mL} /$ $\mathrm{min} / 1.73 \mathrm{~m}^{2}$ during the follow-up visits. Subjects who were lost to follow-up were censored at the date of the last examination.

\section{Statistical analysis}

Statistical analyses were performed using IBM SPSS software for Windows V.23.0. Continuous variables are presented as means and SD. The normality of the distribution was analysed using the Kolomogorov-Smirnov test. Variables not normally distributed were expressed as median and IQR and compared with the Jonckheere-Terpstra test. Categorical variables are expressed as frequencies and percentages. The characteristics of the subjects from each group were compared using one-way analysis of variance and two-sample t-test for continuous variables, or $\chi^{2}$ test for categorical variables. Post hoc analyses were done with the Scheffe method. The associations between the variables were compared using Pearson's $r$ for continuous variables and Spearman's rho for categorical variables. The cumulative incidence of CKD by snoring frequency was assessed using Kaplan-Meier plots. The Cox proportional hazards model was applied to determine the independent association between snoring frequency and incident CKD after adjustment for confounding variables. Variables that showed statistical significance in univariate regression analyses, as well as factors known to have clinical implication on CKD development, were selected for the adjustment models; model I included age and sex, model II included socioeconomic and lifestyle variables, and model III included anthropometry and laboratory features. Proportional hazards assumptions were confirmed using Schoenfeld residuals. The snoring frequency groups were considered 
as non-time-dependent variables, while SBP, WHR, fasting glucose and LDL-C were treated as time-dependent variables. The results were expressed as HRs with 95\% CI. $P$ values less than 0.05 were considered statistically significant.

\section{Patient and public involvement}

Patients and the public were not involved in the design and conduct of this study. The results will not be disseminated to study participants.

\section{RESULTS}

\section{Baseline characteristics}

The baseline characteristics of the study population are shown in table 1 . The mean age of the subjects was $52.0 \pm 8.9$ years, and $48.2 \%$ of them were male. The average eGFR was $93.8 \pm 13.0 \mathrm{~mL} / \mathrm{min} / 1.73 \mathrm{~m}^{2}$. Among the 5569 $(61.5 \%)$ subjects who snored, $3749(67.3 \%)$ subjects were included in the snoring frequency $<1$ day/week group, and $1820(32.7 \%)$ subjects were included in the snoring frequency $\geq 1$ day/week group. More men were included in the snoring frequency $\geq 1$ day/week group than in the non-snorer or the snoring frequency $<1$ day/week group. The WHR, SBP and DBP tended to be higher in subjects who snored more frequently. Individuals who snored more frequently were more likely to be current smokers or alcohol drinkers. The prevalence of comorbidities such as hypertension, diabetes mellitus, myocardial infarction, cerebrovascular attack and MetS tended to be higher in subjects who snored more frequently. Regarding laboratory parameters, fasting glucose, Tchol, TG and LDL-C levels were higher, while HDL levels were lower in frequent snorers. Additional post hoc analyses of the baseline variables are shown in online supplementary table 1 .

\section{Relationship of sleep quality with snoring frequency}

The prevalence of insomnia, having difficulty falling asleep, waking during the night, waking too early in the morning, having irregular sleep time, having symptoms of restless legs syndrome and having periodic limb movements during sleep were comparable among never snorers and snorers. However, ESS was significantly higher in individuals who snored $\geq 1$ day/week than in those who snored less frequently and those who never snored. In addition, the prevalence of EDS was higher in the snoring frequency $\geq 1$ day/week group than that in other groups (table 2).

\section{Development of incident CKD}

During a mean follow-up duration of 8.9 years, 264 $(7.6 \%), 314(8.4 \%)$, and $186(10.2 \%)$ subjects developed CKD in the non-snorer group, $<1$ day/week snoring group and $\geq 1$ day/week snoring group, respectively. A total of $874(9.6 \%)$ participants were lost to follow-up, and the number of subjects lost to follow-up in the non-snorer group, snoring frequency $<1$ day/week group and $\geq 1$ day/ week group were 369 (10.56\%), 336 (8.96\%) and 169 $(9.29 \%)$, respectively. The proportion of participants lost to follow-up were comparable among the groups $(\mathrm{p}=0.06)$.

\section{Impact of snoring on incident CKD}

Kaplan-Meier plots showed that the time to development of incident CKD was significantly shorter in subjects with a snoring frequency of $\geq 1$ day/week than in those with a snoring frequency of $<1$ day/week, and non-snorers (figure 2).

Cox proportional hazards model analyses revealed that the risk of development of CKD was significantly higher in subjects who snored $\geq 1$ day/week than in non-snorers (HR $1.36,95 \%$ CI 1.13 to $1.64, \mathrm{p}<0.01$ ). This finding was significant even after adjustments were made for confounding factors, including age, sex, monthly income, alcohol, smoking status, SBP, WHR, fasting glucose, calculated LDL-C (HR 1.23, 95\% CI 1.09 to $1.38, \mathrm{p}<0.01$ ) (table 3). An additional analysis with adjustment for BMI instead of WHR revealed similar results (online supplementary table 2). The proportional hazards assumption held reasonably for snoring frequency (online supplementary figure 1 ).

\section{DISCUSSION}

In this study, the prevalence of snoring and its impact on renal function were investigated in subjects with normal kidney function. In a sleep quality questionnaire, more than $60 \%$ of the adult population responded that they were snorers. Those who snored frequently were more likely to be associated with metabolic abnormalities. In addition, frequent snorers were found to be related with a significantly increased risk of development of incident CKD.

Several recent studies have evaluated the association between sleep parameters and CKD. An evaluation of Chinese adults showed that overall sleep quality was closely related with high risk of CKD ${ }^{21}$ In addition, a study examining Chronic Renal Insufficiency Cohort participants revealed that shorter sleep duration and greater sleep fragmentation were associated with lower eGFR. ${ }^{22}$ However, in contrast with the results of the current investigation, none of these investigations found a significant relationship between snoring and kidney function. The fact that these previous reports were cross sectional evaluations, compared with the prospective design of this study, could be one of the reasons for this disparity.

Recent investigations have suggested possible associations between OSA and decreased renal function. A retrospective analysis of a national health insurance database showed that, compared with the general population, those diagnosed with sleep apnoea were at an increased risk of CKD. ${ }^{12}$ Similarly, another large-scale retrospective cohort study from Japan reported that an apnoea-hypopnoea index greater than 5 was clearly associated with an increased OR for CKD. ${ }^{23}$ However, few of the previous 
Table 1 Baseline characteristics of patients according to snoring frequency

\section{Snoring frequency}

\begin{tabular}{|c|c|c|c|}
\hline $\begin{array}{l}\text { Non-snorer } \\
(n=3493 \text {, men } \\
42.3 \%)\end{array}$ & $\begin{array}{l}<1 \text { day/week } \\
(n=3749, \text { men } \\
49.9 \%)\end{array}$ & $\begin{array}{l}\geq 1 \text { day/week } \\
(n=1820, \text { men } \\
56.2 \%)\end{array}$ & $\begin{array}{l}\text { Total } \\
\text { (N=9062, men } \\
48.2 \%)\end{array}$ \\
\hline
\end{tabular}

Demographic data

\begin{tabular}{|c|c|c|c|c|c|}
\hline Age (years) & $52.1 \pm 9.2$ & $51.5 \pm 8.6$ & $52.9 \pm 8.6$ & $52.0 \pm 8.9$ & $<0.01$ \\
\hline $\mathrm{BMI}\left(\mathrm{kg} / \mathrm{m}^{2}\right)$ & $23.7 \pm 3.0$ & $24.7 \pm 3.1$ & $25.7 \pm 3.2$ & $24.5 \pm 3.1$ & $<0.01$ \\
\hline Waist:hip ratio (\%) & $80.3 \pm 8.7$ & $82.8 \pm 8.5$ & $86.0 \pm 8.3$ & $82.5 \pm 8.8$ & $<0.01$ \\
\hline $\mathrm{SBP}(\mathrm{mm} \mathrm{Hg})$ & $119.6 \pm 18.3$ & $121.0 \pm 18.0$ & $124.1 \pm 18.0$ & $121.1 \pm 18.2$ & $<0.01$ \\
\hline $\mathrm{DBP}(\mathrm{mm} \mathrm{Hg})$ & $78.8 \pm 11.3$ & $80.3 \pm 11.4$ & $82.4 \pm 11.3$ & $80.1 \pm 11.4$ & $<0.01$ \\
\hline MAP $(\mathrm{mm} \mathrm{Hg})$ & $92.4 \pm 13.0$ & $93.9 \pm 13.0$ & $96.3 \pm 12.7$ & $93.8 \pm 13.0$ & $<0.01$ \\
\hline Monthly income $<\$ 1090$ & $1314(37.6)$ & $1165(31.1)$ & $626(34.4)$ & 3105 (34.3) & $<0.01$ \\
\hline Married & 3421 (97.9) & $3693(98.5)$ & $1800(98.9)$ & $8914(98.4)$ & $<0.06$ \\
\hline $\begin{array}{l}\text { Education duration }>9 \\
\text { years }\end{array}$ & $1414(40.5)$ & $1744(46.5)$ & $838(46.0)$ & $3996(44.1)$ & $<0.01$ \\
\hline Smoking status & & & & & $<0.01$ \\
\hline Never & $2215(63.4)$ & 2135 (56.9) & $932(51.2)$ & $5282(58.3)$ & \\
\hline Former & $469(13.4)$ & $611(16.3)$ & $342(18.8)$ & $1422(15.7)$ & \\
\hline Current & $809(23.2)$ & $1003(26.8)$ & $546(30.0)$ & $2358(26.0)$ & \\
\hline Alcohol status & & & & & $<0.01$ \\
\hline Never & $1752(50.2)$ & $1633(43.6)$ & $746(41.0)$ & $4131(45.6)$ & \\
\hline Former & $234(6.7)$ & $238(6.2)$ & $110(6.0)$ & $582(6.4)$ & \\
\hline Current & $1499(42.9)$ & $1869(50.0)$ & $957(52.6)$ & $4325(47.7)$ & \\
\hline \multicolumn{6}{|l|}{ Comorbidities } \\
\hline HTN & 359 (10.3) & $577(15.4)$ & $360(19.8)$ & $1296(14.3)$ & $<0.01$ \\
\hline DM & $199(5.7)$ & $238(6.3)$ & $146(8.0)$ & $583(6.4)$ & $<0.01$ \\
\hline MI & $20(0.6)$ & $27(0.7)$ & $22(1.2)$ & $69(0.8)$ & 0.04 \\
\hline $\mathrm{CHF}$ & $1(0.0)$ & $11(0.3)$ & $6(0.3)$ & $18(0.2)$ & 0.02 \\
\hline CVA & $26(0.7)$ & $38(1.0)$ & $30(1.6)$ & $94(1.0)$ & 0.01 \\
\hline MetS & $595(17.0 \%)$ & $862(23.0 \%)$ & $575(31.6 \%)$ & $2032(22.4 \%)$ & $<0.01$ \\
\hline \multicolumn{6}{|l|}{ Laboratory parameters } \\
\hline eGFR $\left(\mathrm{mL} / \mathrm{min} / 1.73 \mathrm{~m}^{2}\right)$ & $93.4 \pm 13.0$ & $93.9 \pm 13.0$ & $96.3 \pm 13.0$ & $93.8 \pm 13.0$ & $<0.01$ \\
\hline BUN (mg/dL) & $14.0 \pm 3.6$ & $14.3 \pm 3.5$ & $14.7 \pm 3.7$ & $14.3 \pm 3.6$ & $<0.01$ \\
\hline Creatinine $(\mathrm{mg} / \mathrm{dL})$ & $0.81 \pm 0.16$ & $0.84 \pm 0.17$ & $0.86 \pm 0.17$ & $0.83 \pm 0.17$ & $<0.01$ \\
\hline Haemoglobin (g/L) & $134 \pm 16$ & $137 \pm 16$ & $139 \pm 15$ & $136 \pm 16$ & $<0.01$ \\
\hline Haematocrit (\%) & $40.5 \pm 4.5$ & $41.2 \pm 4.6$ & $41.8 \pm 4.4$ & $41.1 \pm 4.6$ & $<0.01$ \\
\hline Albumin (g/dL) & $4.2 \pm 0.3$ & $4.3 \pm 0.3$ & $4.2 \pm 0.3$ & $4.2 \pm 0.3$ & $<0.01$ \\
\hline CRP (mg/L) & $0.1(0.1-0.2)$ & $0.1(0.1-0.3)$ & $0.2(0.1-0.3)$ & $0.1(0.1-0.3)$ & $<0.01$ \\
\hline Fasting glucose (mg/dL) & $85.7 \pm 21.2$ & $87.6 \pm 21.2$ & $89.9 \pm 22.2$ & $87.4 \pm 21.5$ & $<0.01$ \\
\hline Tchol (mg/dL) & $187.0 \pm 35.5$ & $192.9 \pm 35.8$ & $195.4 \pm 35.0$ & $191.1 \pm 35.7$ & $<0.01$ \\
\hline $\mathrm{HDL}(\mathrm{mg} / \mathrm{dL})$ & $51.1 \pm 12.4$ & $49.1 \pm 11.6$ & $47.7 \pm 11.1$ & $49.6 \pm 11.9$ & $<0.01$ \\
\hline $\mathrm{TG}(\mathrm{mg} / \mathrm{dL})$ & $114.0(80.0-167.0)$ & $126.0(88.0-183.5)$ & $140.0(98.0-205.0)$ & $124.0(87.0-181.0)$ & $<0.01$ \\
\hline LDL-C (mg/dL) & $111.4 \pm 32.2$ & $116.3 \pm 33.0$ & $116.5 \pm 33.1$ & $114.5 \pm 32.8$ & $<0.01$ \\
\hline
\end{tabular}

Data are presented as mean \pm SD, number (\%) or median and IQRs.

.BMI, body mass index; BUN, blood urea nitrogen; CHF, congestive heart failure; CRP, C reactive protein; CVA, cerebrovascular accident; DBP, diastolic blood pressure; DM, diabetes mellitus; HDL, high-density lipoprotein; HTN, hypertension; LDL-C, low-density lipoprotein cholesterol; MAP, mean arterial pressure; MI, myocardial infarction; MetS, metabolic syndrome; SBP, systolic blood pressure; TG, triglyceride; Tchol, total cholesterol; eGFR, estimated glomerular filtration rate. 
Table 2 Relationship of sleep quality with snoring frequency

\begin{tabular}{lccccc}
\hline & Non-snorer & $<$ day/week & $\geq 1$ day/week & \multicolumn{1}{l}{ Total } & P value \\
\hline Insomnia & $595(17.0)$ & $568(15.2)$ & $294(16.2)$ & $1457(16.1)$ & 0.08 \\
Have difficulty falling asleep & $464(13.3)$ & $450(12.0)$ & $230(12.6)$ & $1144(12.6)$ & 0.24 \\
$\begin{array}{l}\text { Wake up during the night and not be able to fall } \\
\text { back sleep }\end{array}$ & $482(13.8)$ & $462(12.3)$ & $242(13.3)$ & $1186(13.1)$ & 0.15 \\
Wake up too early in the morning & $309(8.8)$ & $331(8.8)$ & $176(9.7)$ & $816(9.0)$ & 0.57 \\
Have irregular sleeping time & $2605(74.6)$ & $2807(74.9)$ & $1374(75.5)$ & $6786(74.9)$ & 0.78 \\
Have the symptoms of restless legs syndrome & $377(10.8)$ & $461(12.3)$ & $227(12.5)$ & $1065(11.8)$ & 0.08 \\
$\begin{array}{l}\text { Have experienced periodic limb movements during } \\
\text { sleep }\end{array}$ & $560(16.0)$ & $651(17.4)$ & $323(17.7)$ & $1534(16.9)$ & 0.20 \\
Sleep time & $6.8 \pm 1.4$ & $6.7 \pm 1.3$ & $6.7 \pm 1.4$ & $6.7 \pm 1.4$ & 0.60 \\
ESS score & $5.6 \pm 4.0$ & $6.2 \pm 3.8$ & $7.1 \pm 4.2$ & $6.1 \pm 4.0$ & $<0.01$ \\
EDS & $361(10.3)$ & $462(12.3)$ & $338(18.6)$ & $1161(12.8)$ & $<0.01$ \\
\hline
\end{tabular}

Data are presented as mean \pm SD or number (\%).

.EDS, excessive daytime sleepiness (ESS $\geq 11$ ); ESS, Epworth Sleepiness Scale.

investigations have reported snoring as a risk factor for development of CKD. Although snoring is considered a symptom of OSA, many subjects who snore do not have sleep apnoea. ${ }^{24-26}$ In addition, EDS and fatigue are reported to be related to habitual snoring regardless of the apnoea-hypopnoea frequency, ${ }^{27}$ Also, a recent study showed that in men with CKD, those with OSA were not more likely to report snoring symptoms. ${ }^{4}$ Collectively, these pieces of evidence suggest a possibility of snoring possessing a risk independent from OSA. Studies showing that the vibration induced by snoring induces airway inflammation, which could subsequently act as a systemic inflammatory source, support this possibility. ${ }^{28-30}$ Another point to consider is that the simple measure of self-reported snoring could also be useful as a public health screening tool. Given that polysomnography is expensive and time consuming, understanding how self-reported snoring is related to CKD is clinically significant.

The cause-effect relationship between renal function decline and snoring has been debatable, posing a possibility of both diseases being possible risk factors for each other. CKD may lead to snoring by various mechanisms, including changes in the balance of circulating interleukin-1 beta and tumour necrosis factor-alpha, ${ }^{31}$ pharyngeal stenosis caused by fluid overload and accumulation of uraemic toxins. ${ }^{32-34}$ It is also increasingly recognised that snoring promotes loss of kidney function. Animals exposed to intermittent hypoxia experienced histopathological kidney damage through potential mechanisms, such as renal hypoxia, hypertension, activation of the endothelial dysfunctional sympathetic nervous system and increased oxidative stress. ${ }^{35-37}$ Recently, a cross-sectional

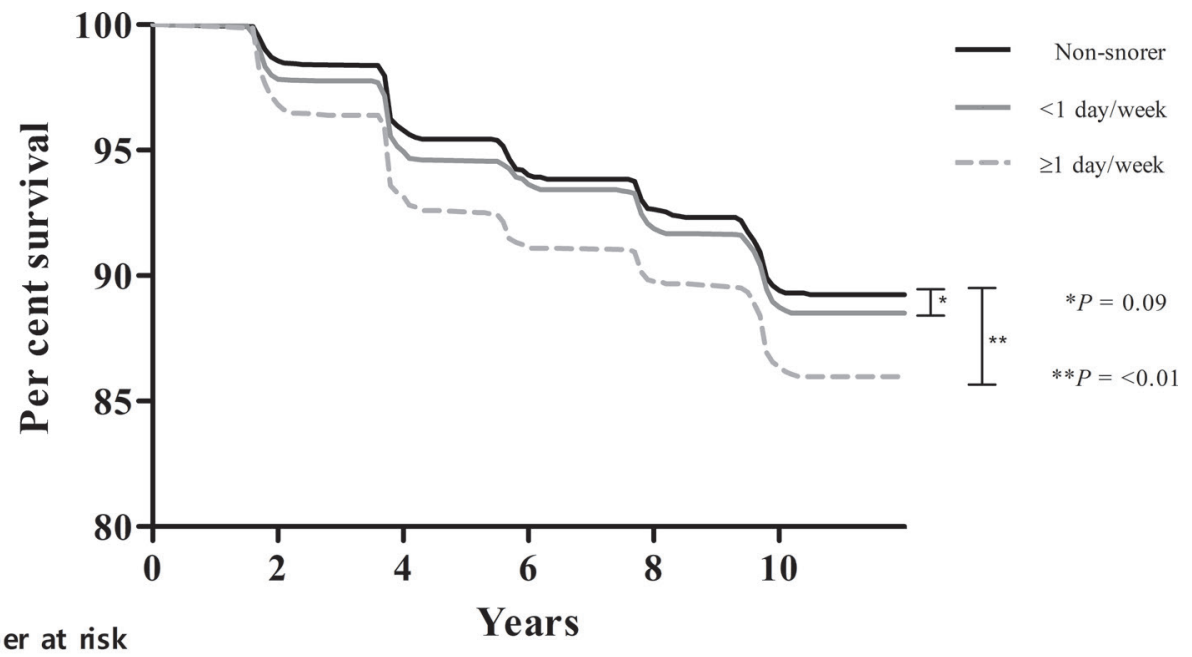

Number at risk

$\begin{array}{lllllll}\text { Non-snorer } & 3493 & 2900 & 2611 & 2424 & 2227 & 1899 \\ <1 \text { day/week } & 3749 & 3162 & 2852 & 2653 & 2450 & 2102 \\ \geq 1 \text { day/week } & 1820 & 1524 & 1345 & 1234 & 1149 & 972\end{array}$

Figure 2 Kaplan-Meier curve for development of incident chronic kidney disease according to snoring frequency. 
Table 3 Relative risk of incident chronic kidney disease according to snoring frequency assessed by Cox regression analysis

\begin{tabular}{|c|c|c|c|c|c|c|}
\hline & \multicolumn{2}{|l|}{ Model I } & \multicolumn{2}{|l|}{ Model II } & \multicolumn{2}{|l|}{ Model III } \\
\hline & HR $(95 \% \mathrm{Cl})$ & $P$ value & HR $(95 \% \mathrm{Cl})$ & $P$ value & HR $(95 \% \mathrm{Cl})$ & $P$ value \\
\hline Non-snorer & 1 (reference) & & 1 (reference) & & 1 (reference) & \\
\hline$\geq 1$ day/week & $1.36(1.13$ to 1.64$)$ & $<0.01$ & 1.34 (1.11 to 1.62$)$ & $<0.01$ & 1.23 (1.09 to 1.38$)$ & $<0.01$ \\
\hline
\end{tabular}

Note: model I: adjusted for age and sex. Model II: model I+monthly income, alcohol status and smoking status. Model III: model II+SBP, waist:hip ratio, fasting glucose and low-density lipoprotein cholesterol.

SBP, systolic blood pressure.

analysis of middle-aged and elderly Chinese individuals has reported self-reported snoring to be closely associated with CKD ${ }^{38}$ However, owing to the cross-sectional design of their study, it was impossible to infer whether snoring increased the risk of CKD or whether the decreased renal function induced snoring frequency in this population. By prospectively observing the renal outcome of subjects with normal renal function, the results of this study could better delineate the cause-effect relationship between CKD and snoring, suggesting that snoring may increase the risk of renal function decline.

The prevalence of MetS was more common among snorers compared with non-snorers. This relationship between snoring and metabolic abnormality is in concordance with previous reports. Snoring was related to elevated blood pressure in pregnant women and in patients with diabetes, as well as in the general population. ${ }^{39-41}$ Dyslipidaemia was more prevalent in children who snored..$^{42}$ In addition, snoring was shown to increase the risk of development of type 2 diabetes. ${ }^{43}{ }^{44}$ Since these metabolic derangements as well as MetS itself are well-known risk factors for development of CKD, it is probable that these snoring-induced metabolic abnormalities mediated the renal function decline observed in frequent snorers. However, the fact that increased snoring frequency was significantly associated with increased risk of CKD, even after adjustments were made for metabolic factors, suggests the possibility that factors other than metabolic derangements may play a role. Further investigations are required to better elucidate the mediators between snoring and renal function decline.

This study has several limitations. First, the use of self-reported questionnaires rather than objective measurements could limit the reliability of the study findings. Although the correlation between self-reports of snoring and objective measures has not been well evaluated yet, self-reported snoring has been reported to be associated with various clinical outcomes in several studies. ${ }^{7-9} 404144$ This suggests the practical usefulness of such questionnaires in stratifying clinical risks. In addition, objective studies such as using microphone recordings, which are based on observations recorded in a single night, may not reflect the usual sleep status. However, questionnaires that ask about average sleep patterns could better reflect the usual condition. Second, the fact that self-assessment of snoring was validated by bed partners or family members could open chance of bias for those who live alone. Assuming that those without spouses would most likely be living alone, the prevalence of snorers among those without spouses was further compared. The proportion of snorers among those with spouses were significantly higher among those who did not currently live with a spouse (online supplementary table 3 ). However, when the current spouse status was included in the adjustment model, the significance of the main analysis was maintained, suggesting that the abovementioned bias possibility did not considerably affect the relationship between snoring and CKD incidence (online supplementary table 4). Third, distinguishing apnoeic from non-apnoeic snoring was not possible. However, knowledge of the risks associated with the snoring symptom, whether or not associated with OSA, could have clinical importance.

\section{CONCLUSION}

In conclusion, self-reported habitual snoring is a significant risk factor for development of CKD in individuals with normal renal function. Self-reported snoring may be an effective and easy early screening method for risk stratification of patients with CKD. However, further investigations are warranted to conclude whether introduction of interventions for snoring could decrease the risk of CKD development.

Acknowledgements The epidemiological data used in this study were obtained from the Korea National Health and Nutrition Examination Survey (KNHANES IV, V and VI) from 2007 to 2014, Republic of Korea. The results and findings have been previously published as an abstract at the 56th ERA-EDTA congress.

Contributors Research idea and study design: CL and JTP. Data acquisition: YSJ, SL, SK and JK. Data analysis/interpretation: KHN, H-RY and JTP. Statistical analysis: JHJ and HK. Supervision or mentorship: SHH, T-HY, S-WK and JTP. Each author contributed important intellectual content during manuscript drafting and accepts accountability for the overall work by ensuring that questions pertaining to the accuracy or integrity of any portion of the work are appropriately investigated and resolved.

Funding The authors have not declared a specific grant for this research from any funding agency in the public, commercial or not-for-profit sectors.

Competing interests None declared.

Patient consent for publication Not required.

Provenance and peer review Not commissioned; externally peer reviewed.

Data availability statement Data are available upon reasonable request. 
Open access This is an open access article distributed in accordance with the Creative Commons Attribution Non Commercial (CC BY-NC 4.0) license, which permits others to distribute, remix, adapt, build upon this work non-commercially, and license their derivative works on different terms, provided the original work is properly cited, appropriate credit is given, any changes made indicated, and the use is non-commercial. See: http://creativecommons.org/licenses/by-nc/4.0/.

\section{REFERENCES}

1. Hill NR, Fatoba ST, Oke JL, et al. Global prevalence of chronic kidney disease - a systematic review and meta-analysis. PLoS One 2016;11:e0158765.

2. Levey AS, Eckardt K-U, Tsukamoto Y, et al. Definition and classification of chronic kidney disease: a position statement from kidney disease: improving global outcomes (KDIGO). Kidney Int 2005;67:2089-100.

3. Heinzer R, Vat S, Marques-Vidal P, et al. Prevalence of sleepdisordered breathing in the general population: the HypnoLaus study. Lancet Respir Med 2015;3:310-8.

4. Adams RJ, Appleton SL, Vakulin A, et al. Chronic kidney disease and sleep apnea association of kidney disease with obstructive sleep apnea in a population study of men. Sleep 2017;40. doi:10.1093/ sleep/zsw015. [Epub ahead of print: 01 Jan 2017].

5. Young T, Finn L, Hla KM, et al. Snoring as part of a dose-response relationship between sleep-disordered breathing and blood pressure. Sleep 1996;19(10 Suppl):S202-5.

6. Resta O, Foschino Barbaro MP, Bonfitto P, et al. Low sleep quality and daytime sleepiness in obese patients without obstructive sleep apnoea syndrome. J Intern Med 2003;253:536-43.

7. Hu FB, Willett WC, Manson JE, et al. Snoring and risk of cardiovascular disease in women. J Am Coll Cardiol 2000;35:308-13.

8. Koskenvuo M, Kaprio J, Telakivi T, et al. Snoring as a risk factor for ischaemic heart disease and stroke in men. BMJ 1987;294:16-19.

9. Li D, Liu D, Wang X, et al. Self-Reported habitual snoring and risk of cardiovascular disease and all-cause mortality. Atherosclerosis 2014;235:189-95.

10. Ogna A, Ogna VF, Rubio JH, et al. Sleep characteristics in early stages of chronic kidney disease in the HypnoLaus cohort. Sleep 2016;39:945-53.

11. Canales MT, Lui L-Y, Taylor BC, et al. Renal function and sleep-disordered breathing in older men. Nephrology Dialysis Transplantation 2008;23:3908-14.

12. Chu H, Shih C-J, Ou S-M, et al. Association of sleep apnoea with chronic kidney disease in a large cohort from Taiwan. Respirology 2016;21:754-60.

13. Molnar MZ, Mucsi I, Novak M, et al. Association of incident obstructive sleep apnoea with outcomes in a large cohort of US veterans. Thorax 2015;70:888-95.

14. Kim Y, Han B-G, KoGES group. Cohort profile: the Korean genome and epidemiology study (KoGES) Consortium. Int J Epidemiol 2017;46:e20.

15. Friedewald WT, Levy RI, Fredrickson DS. Estimation of the concentration of low-density lipoprotein cholesterol in plasma, without use of the preparative ultracentrifuge. Clin Chem 1972;18:499-502.

16. Levey AS, Stevens LA, Schmid $\mathrm{CH}$, et al. A new equation to estimate glomerular filtration rate. Ann Intern Med 2009;150:604-12.

17. Buysse DJ, Hall ML, Strollo PJ, et al. Relationships between the Pittsburgh sleep quality index (PSQI), Epworth Sleepiness scale (ESS), and clinical/polysomnographic measures in a community sample. J Clin Sleep Med 2008;4:563-71.

18. Johns MW. A new method for measuring daytime sleepiness: the Epworth Sleepiness scale. Sleep 1991;14:540-5.

19. Expert Panel on Detection, Evaluation, and Treatment of High Blood Cholesterol in Adults. Executive summary of the third report of the National cholesterol education program (NCEP) expert panel on detection, evaluation, and treatment of high blood cholesterol in adults (adult treatment panel III). JAMA 2001;285:2486-97.

20. Lee SY, Park HS, Kim DJ, et al. Appropriate waist circumference cutoff points for central obesity in Korean adults. Diabetes Res Clin Pract 2007;75:72-80.
21. Li J, Huang Z, Hou J, et al. Sleep and CKD in Chinese adults: a cross-sectional study. CJASN 2017;12:885-92.

22. Knutson KL, Lash J, Ricardo AC, et al. Habitual sleep and kidney function in chronic kidney disease: the chronic renal insufficiency cohort study. J Sleep Res 2018;27:283-91.

23. Iseki K, Tohyama K, Matsumoto $\mathrm{T}$, et al. High prevalence of chronic kidney disease among patients with sleep related breathing disorder (SRBD). Hypertens Res 2008;31:249-55.10.1291/hypres.31.249

24. Lugaresi E, Cirignotta F, Coccagna G, et al. Snoring and the obstructive apnea syndrome. Electroencephalogr Clin Neurophysiol Supp/ 1982;(35):421-30.

25. Young T, Palta M, Dempsey J, et al. The occurrence of sleepdisordered breathing among middle-aged adults. N Engl J Med 1993;328:1230-5.

26. Bearpark H, Elliott L, Grunstein R, et al. Snoring and sleep apnea A population study in Australian men. Am J Respir Crit Care Med 1995;151:1459-65.

27. Svensson M, Franklin KA, Theorell-Haglöw J, et al. Daytime sleepiness relates to snoring independent of the apneahypopnea index in women from the general population. Chest 2008;134:919-24.

28. Almendros I, Acerbi I, Puig F, et al. Upper-Airway inflammation triggered by vibration in a rat model of snoring. Sleep 2007;30:225-7.

29. Puig F, Rico F, Almendros I, et al. Vibration enhances interleukin-8 release in a cell model of snoring-induced airway inflammation. Sleep 2005;28:1312-6.

30. Gozal D, Kheirandish L. Oxidant stress and inflammation in the snoring child: confluent pathways to upper airway pathogenesis and end-organ morbidity. Sleep Med Rev 2006;10:83-96.

31. Descamps-Latscha B, Herbelin A, Nguyen AT, et al. Balance between IL-1 beta, TNF-alpha, and their specific inhibitors in chronic renal failure and maintenance dialysis. relationships with activation markers of T cells, B cells, and monocytes. J Immunol 1995;154:882-92.

32. Beecroft JM, Hoffstein V, Pierratos A, et al. Pharyngeal narrowing in end-stage renal disease: implications for obstructive sleep apnoea. European Respiratory Journal 2007;30:965-71.

33. Elias RM, Chan CT, Paul N, et al. Relationship of pharyngeal water content and jugular volume with severity of obstructive sleep apnea in renal failure. Nephrol Dial Transplant 2013;28:937-44.

34. Auckley DH, Schmidt-Nowara W, Brown LK. Reversal of sleep apnea hypopnea syndrome in end-stage renal disease after kidney transplantation. American Journal of Kidney Diseases 1999;34:739-44.

35. Paller MS, Hoidal JR, Ferris TF. Oxygen free radicals in ischemic acute renal failure in the rat. J. Clin. Invest. 1984;74:1156-64.

36. Brodsky SV, Yamamoto T, Tada T, et al. Endothelial dysfunction in ischemic acute renal failure: rescue by transplanted endothelial cells. Am J Physiol Renal Physiol 2002;282:F1140-F1149.

37. Fujii T, Kurata $\mathrm{H}$, Takaoka M, et al. The role of renal sympathetic nervous system in the pathogenesis of ischemic acute renal failure. Eur J Pharmacol 2003;481:241-8.

38. Song J, Wang C, Ma A, et al. Self-Reported snoring is associated with chronic kidney disease independent of metabolic syndrome in middle-aged and elderly Chinese. J Diabetes Investig 2018.

39. Guilleminault C, Querra-Salva M-A, Chowdhuri S, et al. Normal pregnancy, daytime sleeping, snoring and blood pressure. Sleep Med 2000;1:289-97.

40. Koskenvuo M, Partinen M, Sarna S, et al. Snoring as a risk factor for hypertension and angina pectoris. The Lancet 1985;325:893-6.

41. Wang T, Lu J, Wang W, et al. Sleep duration and snoring associate with hypertension and glycaemic control in patients with diabetes. Diabet. Med. 2015;32:1001-7.

42. Gozal D, Capdevila OS, Kheirandish-Gozal L. Metabolic alterations and systemic inflammation in obstructive sleep apnea among nonobese and obese prepubertal children. Am J Respir Crit Care Med 2008;177:1142-9.

43. Elmasry A, Janson C, Lindberg E, et al. The role of habitual snoring and obesity in the development of diabetes: a 10-year follow-up study in a male population. J Intern Med 2000;248:13-20.

44. Al-Delaimy WK, Manson JE, Willett WC, et al. Snoring as a risk factor for type II diabetes mellitus: a prospective study. Am J Epidemiol 2002;155:387-93. 